\title{
Educational attainment and the Brexit vote
}

\author{
Robert Calvert Jump* Jo Michell ${ }^{\dagger}$
}

July 2019

\begin{abstract}
The Brexit vote is the most significant political event in recent British history. We present bivariate choropleth maps comparing the Leave vote share with age-adjusted secondary educational attainment. This provides an immediate visual representation of the spatial and bivariate correlations between these variables, as well as their geographical distribution. Only twelve of the eighty-five local authorities that voting Remain had lower than expected age-adjusted educational attainment; only ten of the ninety-five local authorities in which the Leave vote share exceeded $60 \%$ had higher than expected age-adjusted educational attainment. While the effectiveness of choropleth maps for exploring the spatial characteristics of bivariate relationships has been discussed by a number of authors, our technique of using borders to highlight a threshold value appears to be under-utilised.
\end{abstract}

Keywords: Brexit, education, choropleth.

The vote for the United Kingdom to exit the European Union is the most significant geopolitical event in recent British history, dominating domestic political activity for the last three years. Among the narratives that have emerged to explain the drivers of the United Kingdom's vote to leave the European Union, five broad sets of causal factors can be identified:

1. Factors specific to the Leave and Remain campaigns, including misleading claims, campaign misspending and outside influence via social media.

${ }^{*}$ Department of Accounting, Economics and Finance, University of the West of England, Coldharbour Lane, Bristol, BS16 1QY, UK. Email: rob.calvertjump@uwe.ac.uk.

${ }^{\dagger}$ Department of Accounting, Economics and Finance, University of the West of England, Coldharbour Lane, Bristol, BS16 1QY, UK. Email: jo.michell@uwe.ac.uk. 
2. Cultural factors, such as English nationalism, affinity for authoritarian values, xenophobia or anti-European sentiment.

3. Distributional factors stemming from globalisation, most notably the creation of a "left-behind" group of the economically disenfranchised.

4. Economic factors unrelated to globalisation, including rising inequality and austerity.

5. Demographic factors, such as voting cleavages between the old and the young or those with and without a university education.

Evidence for each of these narratives has been presented since the referendum, and each would no doubt find a place in any comprehensive analysis of the causes of the vote (Becker et al., 2017; Dorling, 2016; Goodwin \& Heath, 2016; Swales, 2016).

Notwithstanding the plurality of possible drivers of Brexit, political scientists have understood for some time that sociodemographic factors such as education, class and geography are fundamental in forming political and cultural identities (Campbell et al., 1960). These identities are relatively inelastic, and thus sociodemographic characteristics are often regarded as one of a small number of deep exogenous variables driving political outcomes: "sociodemographic factors and identities are causally prior to, and shape, political attitudes that in turn are the proximate cause of vote choice" (Hobolt, 2016, p. 1266). The graphic presented in Figure 1 illustrates the power of this hypothesis for a key demographic variable: educational attainment at secondary school level.

The plots are bivariate choropleth maps of England and Wales constructed using (a) cartographic local authority border data and, (b) a stylised map in which each local authority is represented as a hexagon of equal size. The colour of each local authority indicates the proportion of the voting population that voted Leave, and a black border indicates local authorities where secondary educational attainment is less than expected based on the distribution of the population by age and sex.

The age-adjusted education indicator is calculated using the standard approach (e.g. Ahmad et al., 2001) as follows. For each local authority in England and Wales, the percentage of the adult population with fewer than five GCSEs or equivalent is calculated from census data, giving a raw indicator. Since educational attainment will be influenced by the demographic structure of the area in terms of age and sex - each of which are significant covariates of the Leave vote - the raw indicator is adjusted to account for the underlying age structure of each local authority. First, for each five-year age 
and sex cohort (for example, females aged 19 to 24) across the entire population of England and Wales, the population percentage with fewer than five GCSEs is calculated. ${ }^{1}$ A weighted average of these cohort percentages is then used to predict educational attainment for each local authority, using the age and sex structure of the local authority to derive the weights. Finally, the age-adjusted educational attainment indicator is the ratio of actual GCSE attainment to predicted GCSE attainment in each local authority. Areas where this ratio exceeds one (the population percentage with fewer than five GSCEs exceeds the expected percentage) are indicated with a black border.

The plots visualise both the geographical distribution of Leave votes and relative educational attainment, and the bivariate and spatial correlations between the two variables. The utility of choropleth maps in illustrating bivariate relationships has been emphasised by Olson (1981) and Leonowicz (2006), among others, although our particular combination of colour and highlighted borders appears to be rare.

The plot reveals strong correlations, both spatially and between educational attainment and Leave votes. Local authorities where the Leave vote exceeded $60 \%$ are clustered in the Midlands and the east coast. This clustering is closely matched by our educational indicator: in only 10 of the 95 local authorities in which the Leave vote share exceeded $60 \%$ was age-adjusted educational attainment higher than expected. Conversely, only 12 of the 85 local authorities that voted Remain had lower than average high school educational attainment. Seven are cities: Leicester, Norwich, Manchester, Liverpool and Sefton, Newcastle, and Leeds; the remaining five are boroughs in east London that are geographically contiguous with the large cluster of strongly Leave-voting areas in Kent and Essex.

These observations support existing analyses of the relation between education and voting patterns (e.g. Swales, 2016; Becker et al., 2017), and the importance of sociodemographic characteristics as key drivers of the United Kingdom's vote leave the European Union.

\footnotetext{
${ }^{1}$ Data on qualifications, age and sex are taken from the 2011 census. Referendum data are taken from the Electoral Commission. Scotland is excluded because the Scottish census questions on secondary education are not comparable with those in the English and Welsh census. Northern Ireland is excluded due to incomparable referendum data. Since Scotland and Northern Ireland both voted Remain overall, their exclusion means we are focusing solely on the Leave-voting nations of England and Wales.
} 


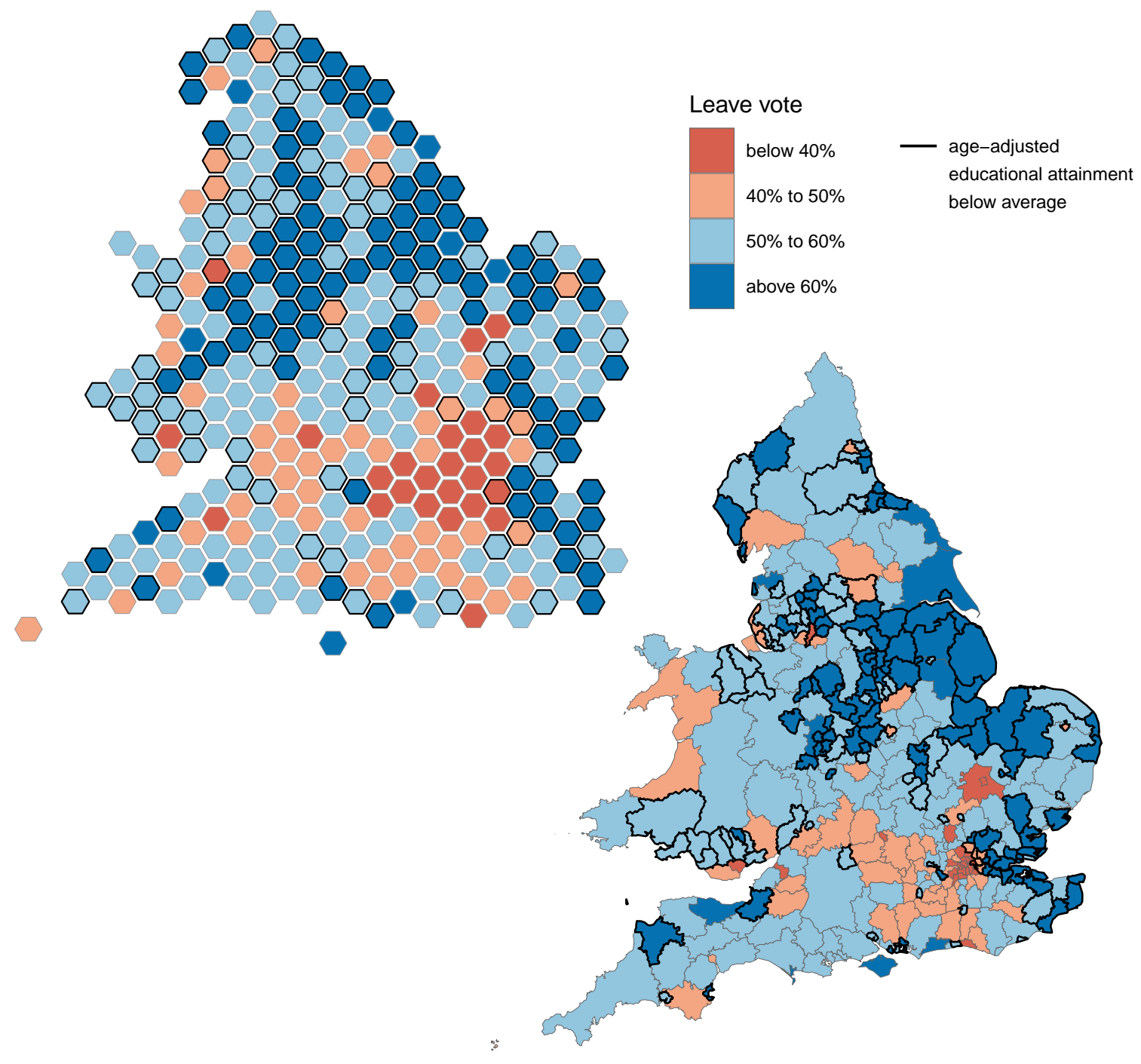

Figure 1: Choropleth map and cartogram hex map of Leave vote share and age-adjusted educational attainment in England and Wales by local authority. 


\section{Acknowledgements and Software}

We are grateful to Danny Dorling for helpful comments and suggestions on an earlier version of this visualisation. Local authority boundary shapefiles were downloaded from the Office for National Statistics Open Geography Portal at http://geoportal.statistics.gov.uk/. The local authority hexagon cartogram shapefile was created by Ben Flanagan and made available under a Creative Commons Licence at http://www.arcgis.com/home/item.html? $i d=593037 b c 399 e 460 b b 7 c 6 c 631 c e f f 67 b 4$

\section{References}

Ahmad, O. B., Boschi-Pinto, C., Lopez, A. D., Murray, C. J., Lozano, R., Inoue, M., et al. (2001). Age standardization of rates: a new who standard. Geneva: World Health Organization, 9(10).

Becker, S. O., Fetzer, T., \& Novy, D. (2017). Who voted for Brexit? A comprehensive district-level analysis. Economic Policy, 32(92), 601-650. URL http://dx.doi.org/10.1093/epolic/eix012

Campbell, A., Converse, P., Miller, W., \& Stokes, D. (1960). The American Voter. Chicago: University of Chicago Press.

Dorling, D. (2016). Brexit: the decision of a divided country. BMJ, 354. URL https ://www.bmj . com/content/354/bmj . i3697

Goodwin, M. J., \& Heath, O. (2016). The 2016 Referendum, Brexit and the Left Behind: An Aggregate-level Analysis of the Result. The Political Quarterly, 87(3), 323-332.

URL https://onlinelibrary.wiley.com/doi/abs/10.1111/ 1467-923X. 12285

Hobolt, S. B. (2016). The Brexit vote: a divided nation, a divided continent. Journal of European Public Policy, 23(9), 1259-1277.

Leonowicz, A. (2006). Two-variable choropleth maps as a useful tool for visualization of geographical relationship. Geografija, 42, 33-37.

Olson, J. M. (1981). Spectrally encoded two-variable maps. Annals of the Association of American Geographers, 71 (2), 259-276.

Swales, K. (2016). Understanding the Leave vote. Working paper, NatCen Social Research. 
URL

http://natcen.ac.uk/media/1319222/natcen_ brexplanations-report-final-web2.pdf 